\title{
Structural Analysis and Optimization of Pitman ARM
}

\author{
Shatabdee Sonawane \\ ME Design Student, Department of Mechanical Engineering \\ Sinhgad Academy of Engineering, \\ Pune, India.
}

\begin{abstract}
Now a day's automotive OEM are concentrating on vehicles efficiency and cost effectiveness to reach out with competitors. In order to achieve cost effectiveness optimization of less critical components is necessary. Pitman arm seems to be an overdesigned part. Pitman arm used to steer vehicle is redesigned and modified for achieving less weight and thus cost. Reverse engineering technique is used to model existing pitman arm by CATIA V5 software. The structural optimization is done on the pitman arm using Optistruct tool. Structure of pitman arm is changed by removing the material from the surface where stress value is low. The testing of Pitman arm is carried out for static analysis and fatigue analysis and the results are compared with the experimental results. Static analysis results of existing pitman arm proved that the model is more stable and there was scope for optimization. The weight of original Pitman arm model was 974 gm and that of the new optimized model $840 \mathrm{gm}$. Weight of the Pitman arm after optimization is reduced by $14 \%$. FEA of optimized Pitman arm has shown 1108.0 microstrain whereas that of the experimental testing shown 1024.39 microstrain. The comparison, between fatigue life results of existing and optimized pitman arm has been performed and it is observed that the pitman arm is having infinite life. The above study confirmed that optimized pitman arm is structurally stable with good fatigue life.
\end{abstract}

\section{INTRODUCTION}

Steering system is one of the important systems of vehicle as it directs the vehicle. Pitman Arm is one of the most important steering system components. Pitman arm is attached to steering gear box which is at the end of steering shaft at one end and other end is connected to Track Rod which is consecutively connected to Idler Arm. Pitman arm is fixed at the steering gear box end and gets its input from the same while other end is attached to track rod with ball joint. Input from the steering gear box is in angular motion. But to steer wheels one needs linear motion. This transmission of angular motion to linear motion is carried by pitman arm and wheels get steered in required direction. Two types of failures occur in Pitman Arm. In normal loading conditions no vibrations are present in pitman arm but in unexpected conditions sudden failure takes place. Pitman arm is fixed at steering gear box and other end is connected to track rod by ball joint. Therefore worning of ball joint takes place and failure occurs [1]. Earlier FEA is used to do the modal analysis, fatigue analysis and optimization of Pitman Arm [2]. CATIA V5 CAD software was used to create 3D model for steering arm. Results of FEA shown scope for material removal from regions where stresses developed are much below the limit deformation was also very less [3]. Hierarchical optimization of steering linkage was done by dividing the system into number of sub-system objective functions. Results revealed that hierarchical optimization procedure is more effective and robust as compared to the

\author{
Prof. P. M. Sonawane \\ Assistant Professor, Department of Mechanical Engineering, \\ Sinhgad Academy of Engineering, \\ Pune, India.
}

simultaneously optimized system [4]. Researcher also studied dynamic simulation of steering mechanism by varying force with respect to time [5]. They concluded that for more safe designs of steering mechanism some importance to dynamic analysis should be given. A new material, austempered ductile material, was proposed for pitman arm. Strength of pitman arm was found to be increased with the new material [6]. New material shown homogeneous microstructure, less prone to failure during the deformation and increased the elongation of the original material making it more deformable.

All above studies indicates the scope for optimization of pitman arm. In present work the Structure of pitman arm is changed by removing the material from the surface where stress value is low. The testing of Pitman arm is carried out for static analysis and fatigue analysis and the results are compared with the experimental results.

\section{ANALyticAl CALCULATiON}

\section{A. Force Calculation}

Force calculations are done analytically to get the magnitude of force acting on steering arm (pitman arm) while driving. Pitman arm of Mahindra Bolero vehicle is selected for analysis and optimization purpose. The total mass of the vehicle is calculated by following equation. Approximate allowed passenger weight and luggage weight for selected vehicle is approximately $360 \mathrm{Kg}$ and $100 \mathrm{Kg}$ respectively.

M1 $=$ Kerb weight + Passenger weight + Luggage

$\mathrm{M} 1=1615+360+100$

M1 $=2075 \mathrm{Kg}$

As we are considering the force on pitman arm front axle weight must be considered as it is subjected to higher load. From total weight, $52 \%$ of the weight is taken by front axle and $48 \%$ is taken by rare axle. Therefore mass on front axle is calculated as,

M2 $=0.52 \times 2075$

M2 $=1079 \mathrm{Kg}$

Load acting on single wheel is

$\mathrm{M} 3=1079 \div 2=539.5 \mathrm{Kg}$

Now from vehicle specifications,

- Width of tire, $B=215 \mathrm{~mm}$

- Center of rotation (King pin) to wheel, $\mathrm{E}=120 \mathrm{~mm}$

- Coefficient of friction, $\mu=0.7$

- Distance from king pin center to tie rod center, $\mathrm{L}=$ $145 \mathrm{~mm}$

The torque required to rotate one wheel is given by, 
$\mathrm{T}=\mathrm{M}_{3} \times \mathrm{g} \times \mu \times \sqrt{\left(\frac{B^{2}}{8}\right)+E^{2}}$

$\mathrm{T}=525965.593 \mathrm{~N}$

But, two front wheels are handled by single steering arm, therefore the force on it will be doubled,

$\mathrm{F}=\frac{T}{L} \times 2$

$\mathrm{F}=7254.767 \mathrm{~N}$

\section{B. Stress Calculations}

Properties of material used for pitman arm are given in table

Table- I: material properties of SAE1022

\begin{tabular}{|c|c|}
\hline Property & Value \\
\hline Young's Modulus (E) & $210 \mathrm{GPa}$ \\
\hline Poisson's Ratio (v) & 0.3 \\
\hline Density ( $\rho)$ & $7.9 \times 10^{-6} \mathrm{~kg} / \mathrm{mm} 3$ \\
\hline Yield Strength & $740 \mathrm{MPa}$ \\
\hline
\end{tabular}

Bending stress induced in the pitman arm is calculated by,

Where,

$$
\sigma=\frac{M y}{I}
$$

$\sigma=$ Maximum bending stress

$M=$ Bending moment

$\mathrm{y}=$ Vertical distance away from the neutral axis

$\mathrm{I}=$ Moment of inertia

Now

$\mathrm{y}=20 \mathrm{~mm}$

$\mathrm{I}=117333.333 \mathrm{~mm}^{4}$

And, $M=\mathrm{F} \times \mathrm{L}_{1}=1197036.555$ N.mm, where $\mathrm{L}_{1}=$ total length of specimen

By putting all these values we get

$\sigma=204.04 \mathrm{Mpa}$

\section{Fatigue Life Calculations}

Number of life cycles completed by pitman arm before failure is calculated by

$S_{a}=$ Stress amplitude

$$
N=10^{\frac{-c}{b}} \times S_{a}^{\frac{1}{2}}
$$

$\mathrm{b}=-\frac{1}{3} \log \frac{0.8 S_{u t}}{S_{e}}$

$\mathrm{c}=\log \frac{\left(0.8 S_{u t}\right)^{2}}{S_{e}}$

$\mathrm{S}_{\mathrm{ut}}=$ Ultimate tensile strength

$\mathrm{S}_{\mathrm{e}}=$ Endurance limit

Now,

$\mathrm{S}_{\mathrm{ut}}=740 \mathrm{Mpa}=75.51 \mathrm{~kg} / \mathrm{mm}^{3}$

For $\mathrm{S}_{\mathrm{a}}=0.8 \times \mathrm{S}_{\mathrm{ut}}=94.387 \mathrm{~kg} / \mathrm{mm}^{3}$

And $\mathrm{S}_{\mathrm{e}}=0.5 \times \mathrm{S}_{\mathrm{ut}}=37.755 \mathrm{~kg} / \mathrm{mm}^{3}$

$\mathrm{b}=-0.3054$

$\mathrm{c}=5.4636$

Now by putting all the values in equation, we get, $N=6.032 \times 10^{18}$
This gives that, pitman arm taken as test specimen will undergo failure after $6.032 \times 10^{18}$ cycles. From this we can say it has infinite life as it exceeds 10 lakh cycles.

\section{FEA ANALYSIS AND OPTIMIZATION}

Now to obtain the approximate numerical solution Finite Element Analysis technique is used with ANSYS software.

\section{A. Static Analysis of Original Pitman arm}

Meshed model of pitman arm is shown in fig. 1. Minimum size of mesh is $0.388140 \mathrm{~mm}$. Number of nodes and elements are 94019 and 28041 respectively. While applying boundary conditions, hole with larger diameter is kept fixed as it is fixed to steering rod. Other end has rotational movement with force $7254.767 \mathrm{~N}$ acting on it. Deformation plot, stress plot and strain plot are shown in fig. 2, fig. 3 and fig. 4 respectively. Maximum deformation of $0.27503 \mathrm{~mm}$ is observed whereas Maximum stress induced is $167.81 \mathrm{MPa}$.

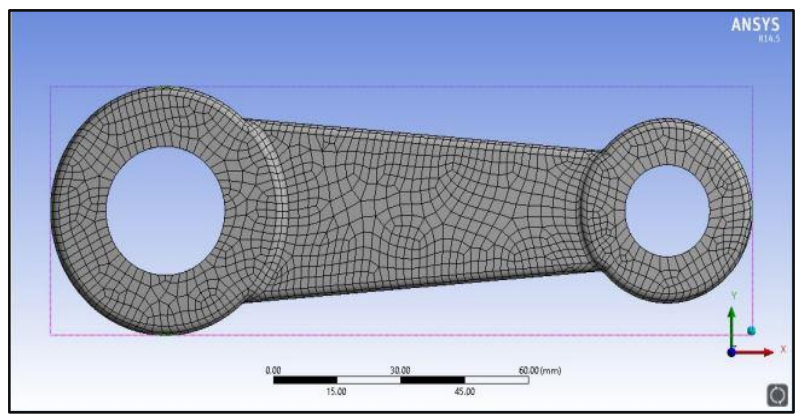

Fig. 1 Meshing of Pitman arm model

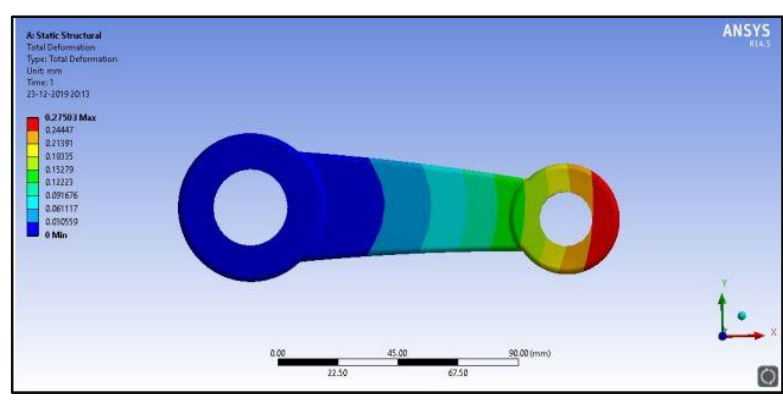

Fig. 2 Deformation plot Pitman Arm

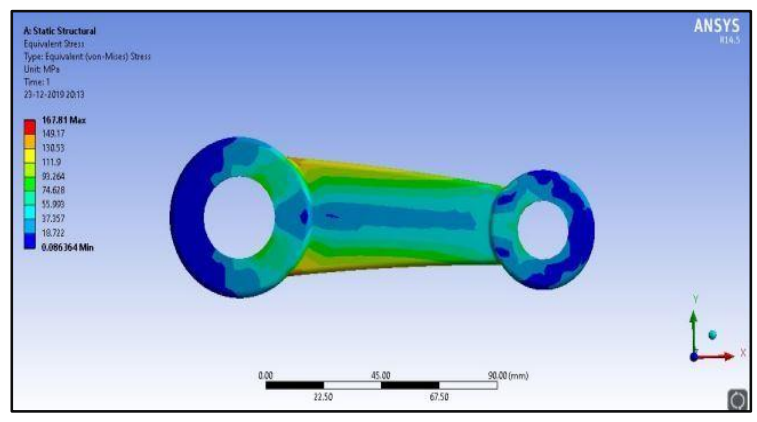

Fig. 3 Stress plot of Pitman arm 


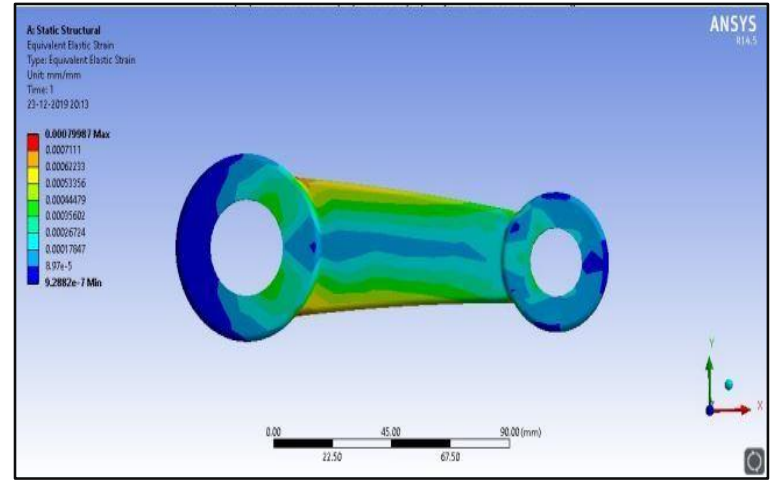

Fig. 4 Strain plot of Pitman arm

Stress plot of pitman arm shows that the induced stress $(162 \mathrm{MPa})$ is well within the limit and deformation is less (Maximum strain $=0.00079987 \mathrm{~mm} / \mathrm{mm}$ ) hence scope for optimization of pitman arm exists.

\section{B. Fatigue Analysis}

Figure 5 shows the fatigue cycle of pitman arm above 1 million cycles. The factor of safety obtained under load conditions is shown in fig. 6 . The factor of safety is maximum at center of pitman arm. It is between 10 to15. In automobile industry the maximum factor of safety required is 2 . Therefore the scope of removal of material at the center of pitman arm exists.

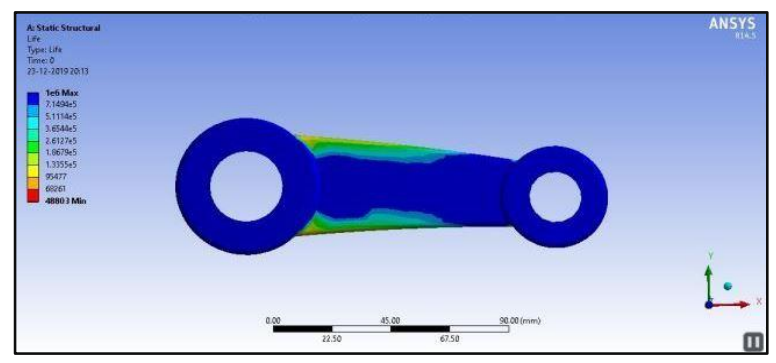

Fig. 5: Fatigue life above 1 million cycles

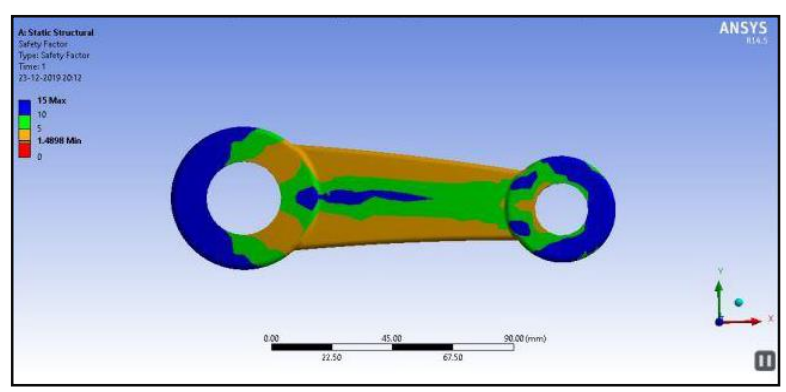

Fig. 6: Factor of Safety

\section{OPTIMIZATION OF PITMAN ARM}

Size of shape of Pitman arm to be machined is decided by trial and error method with the help of ANSYS. Three models have been studied as shown below.

\section{A. Model 1}

First model is developed with the radius $5 \mathrm{~mm}$. Deformation plot and equivalent stress plot is shown in fig. 7 and fig. 8 respectively. Maximum deformation of $0.32136 \mathrm{~mm}$ is seen and Maximum stress induced is $200.69 \mathrm{MPa}$.

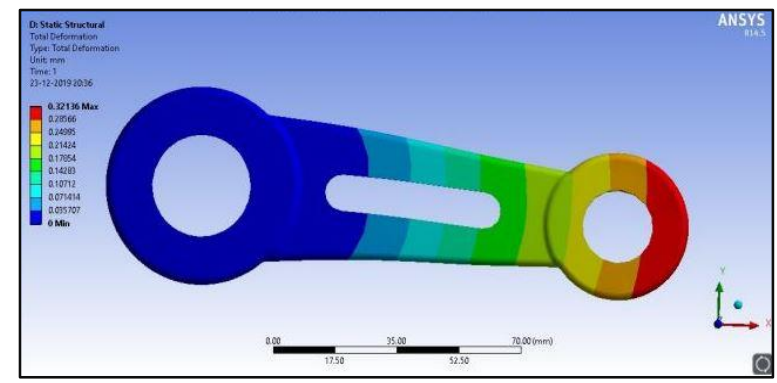

Fig. 7 Total Deformation plot for model 1

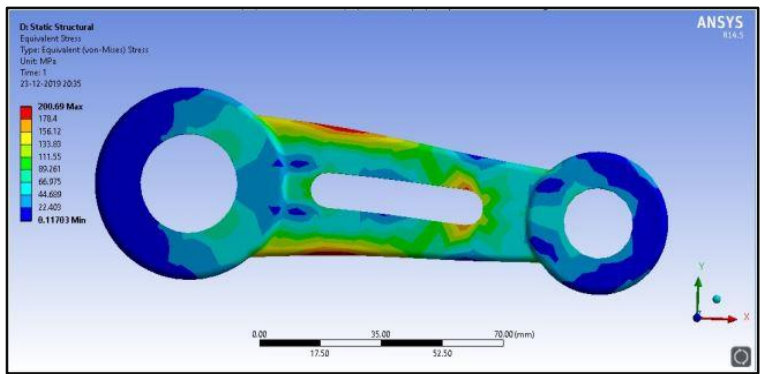

Fig. 8 Equivalent Stress Plot for Model 1

\section{B. Model 2}

Second model is developed with the radius $6 \mathrm{~mm}$. Deformation plot and equivalent stress plot is shown in fig. 9 and fig. 10 respectively. Maximum deformation of 0.34252 $\mathrm{mm}$ is seen and Maximum stress induced is $232.25 \mathrm{MPa}$

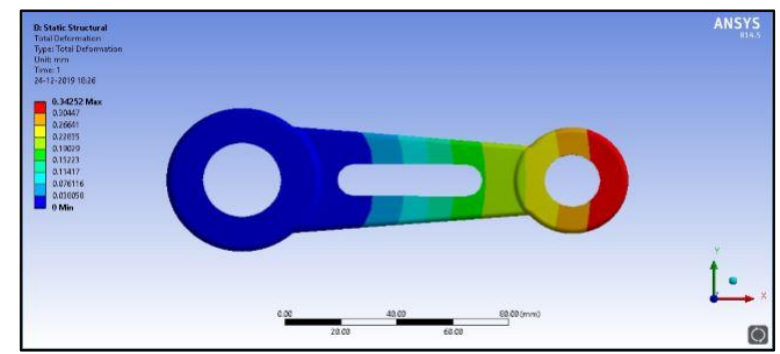

Fig. 9 Total Deformation plot for model 2

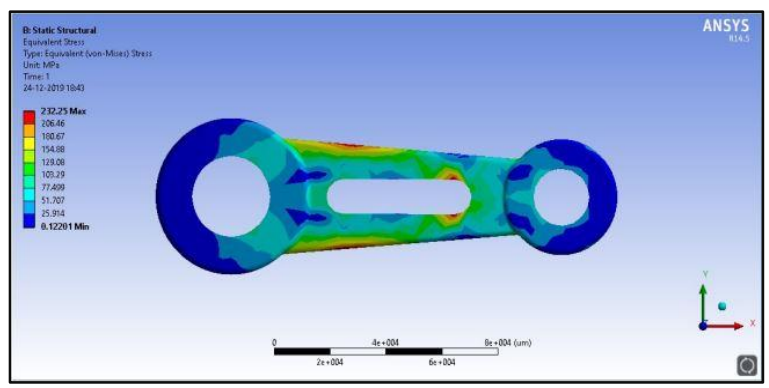

Fig. 10 Equivalent Stress Plot for Model 2 


\section{Model 3}

Third model is developed with the radius $6.25 \mathrm{~mm}$. Deformation plot and equivalent stress plot is shown in fig. 11 and fig. 12 respectively. Maximum deformation of 0.35423 $\mathrm{mm}$ is seen and Maximum stress induced is $255.23 \mathrm{MPa}$

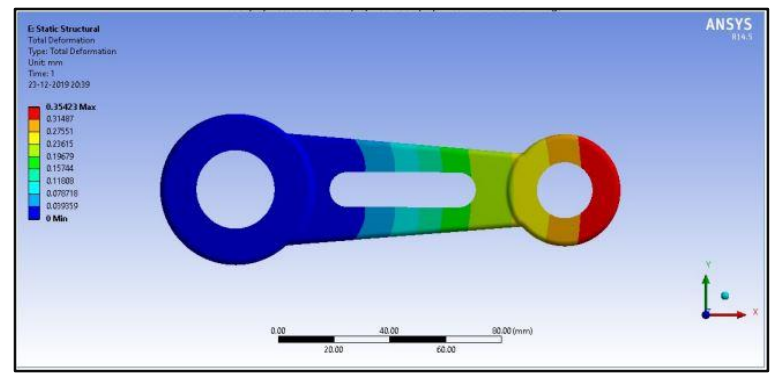

Fig. 11 Total Deformation plot for model 1

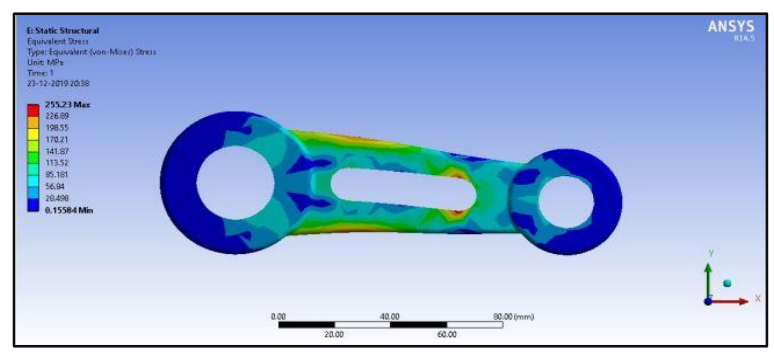

Fig. 12 Equivalent Stress Plot for Model 2

When the results of model 1 , model 2 and model 3 are compared it is observed that the equivalent stress for model 3 is 255.23 MPa which exceeds design stress limit i.e. 246.666 $\mathrm{MPa}$. So the size of model is not suitable. So model 2 having slot size with Radius $6 \mathrm{~mm}$ gives for optimum results. Structural analysis is done for equivalent strain and fatigue life of Modal 2 as shown below. Maximum strain of 0.001108 is observed in model 2.

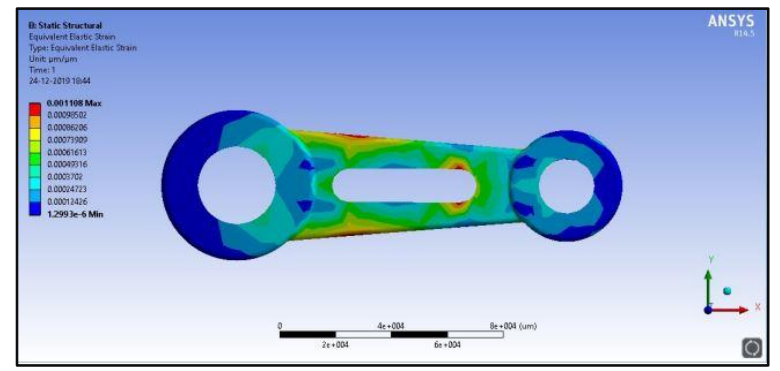

Fig. 13 Equivalent Strain plot for Model 2

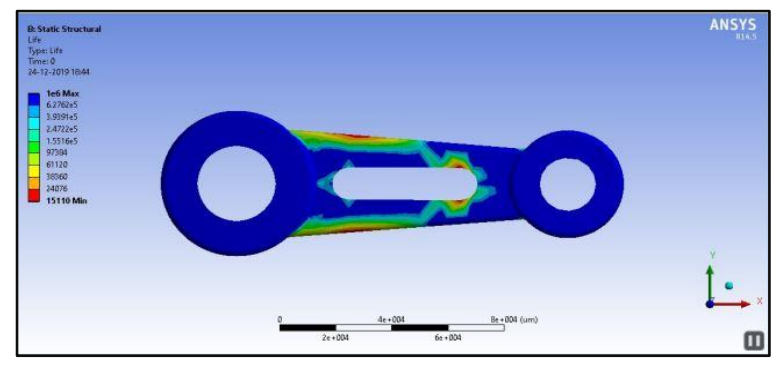

Fig. 14 Fatigue life For Model 2
FEA results of original Pitman arm and optimized model are shown in table II. Comparison is done on the basis of deformation, stress, strain and fatigue cycle.

Table II: FEA results of original Pitman arm and optimized model.

\begin{tabular}{|c|c|c|}
\hline Parameters & $\begin{array}{c}\text { Original pitman } \\
\text { arm }\end{array}$ & $\begin{array}{c}\text { Optimized model with 6 } \\
\text { mm radius and thick slot }\end{array}$ \\
\hline $\begin{array}{c}\text { Deformation } \\
(\mathrm{mm})\end{array}$ & 0.27503 & 0.34252 \\
\hline Stress $(\mathrm{MPa})$ & 161.87 & 232.25 \\
\hline Strain $(\mathrm{mm} / \mathrm{mm})$ & 0.00079987 & 0.001108 \\
\hline $\begin{array}{c}\text { Fatigue life } \\
\text { (cycles) }\end{array}$ & $48803 \times 10^{6}$ & $15110 \times 10^{6}$ \\
\hline
\end{tabular}

Though the deformation, stress and strain of optimized model is increased however it is still in the permissible limit. Also the number of cycles to be completed by Pitman arm is more than 1 million cycle.

\section{EXPERIMENTAL VALIDATIONS}

\section{Manufacturing}

Machining of optimized pitman arm is done by using re-machining original arm. On vertical drilling machine required shape and size slot was created and then finishing is done by using grinder. Drilling slot is developed by using vertical drilling machine. For drilling direct speed of 525 RPM and gear speed of 105 RPM is used. And drill tool of diameter $12 \mathrm{~mm}$ made up of Carbide Centre material is used to drill required size of hole. After this for applying boundary conditions fixture was manufactured. Fig. 15 shows the Pitman arm with fixture. Pitman arm with strain gauge is shown in Figure 17.

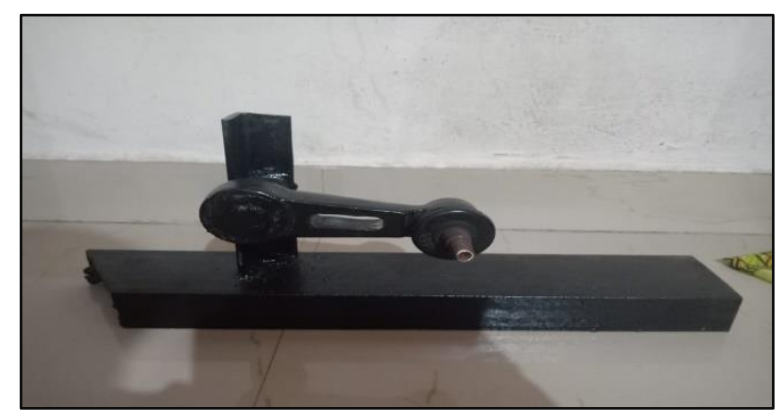

Fig. 15 Pitman arm with fixture applying boundary conditions

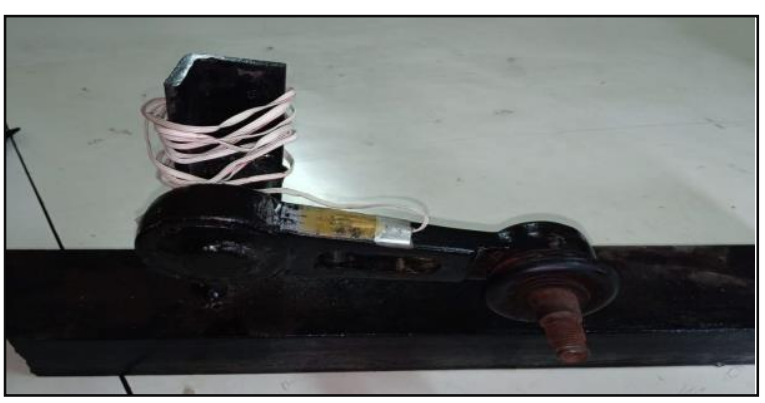

Fig. 16 Pitman arm with strain gauge 


\section{Experimental Testing:}

Universal testing machine was used to apply required load $(.7254 .767 \mathrm{~N})$ at free end of pitman arm. Strain gauge was mounted on Pitman arm. When load was acting on arm strain gauge measured strain induced in the arm using strain logger. Then from these readings strain against stress graph was obtained. And stress is calculated and verified.

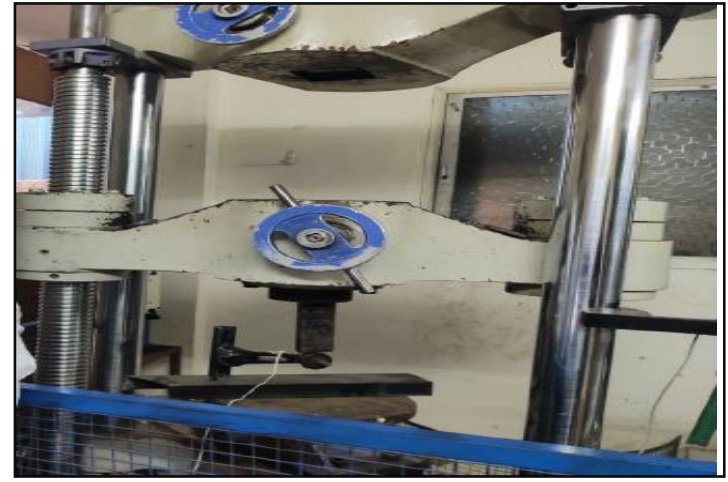

Figure 17: Testing of Pitman arm under UTM

Obtained results of experimental testing are compared with the FEA results. It is shown in table III

\section{RESULTS}

Table III: FEA result for original and optimized model

\begin{tabular}{|c|c|c|}
\hline Model & $\begin{array}{c}\text { Original } \\
\text { model }\end{array}$ & $\begin{array}{c}\text { Optimized model with } 6 \mathrm{~mm} \\
\text { radius and thickness slot }\end{array}$ \\
\hline $\begin{array}{c}\text { Deformation } \\
(\mathrm{mm})\end{array}$ & 0.27503 & 0.34252 \\
\hline Stress $(\mathrm{MPa})$ & 161.87 & 232.25 \\
\hline Strain $(\mathrm{mm} / \mathrm{mm})$ & 0.00079987 & 0.001108 \\
\hline $\begin{array}{c}\text { Fatigue life } \\
\text { (cycles) }\end{array}$ & $48803-1 e^{6}$ & $15110-1 e^{6}$ \\
\hline
\end{tabular}

From Table 4 we can see that, total deformation values for original model and optimized model in ANSYS analysis is negligible. And maximum life is also same.

FEA and Experimental results for Strain:

Now after going for machining and Strain Gauge Testing using UTM as shown in figure 36 we got results for strain induced in the arm as shown in figure 36. Strain induced in pitman arm is 0.001204 , form which stress is calculated as 215.04 which is below the design stress limit.

Table IV: FEA and Experimental strain Results

\begin{tabular}{|c|c|c|}
\hline Model & FEA Strain $(\mathrm{mm} / \mathrm{mm})$ & $\begin{array}{c}\text { Experimental Strain gauge } \\
\text { testing strain }(\mathrm{mm} / \mathrm{mm})\end{array}$ \\
\hline $\begin{array}{c}\text { Optimized } \\
\text { model with 6 } \\
\text { mm radius slot }\end{array}$ & 0.001108 & 0.001204 \\
\hline
\end{tabular}

Weight reduction:

Table V: Weight comparison of original and optimized model

\begin{tabular}{|c|c|c|}
\hline Model & Original Model & Optimized Model \\
\hline Weight (gms) & 974 & 890 \\
\hline
\end{tabular}

From table 4 it can observe that FEA strain results and experimental strain gauge testing results are nearly same and equal. So optimized pitman arm is safe under normal loading conditions. Also the weight of original pitman arm model was
$974 \mathrm{gm}$ and that of the optimized model is $840 \mathrm{gm}$. Therefore weight of the component is reduced successfully upto $14 \%$ after optimization.

\section{CONCLUSION}

1. Static analysis results of existing pitman arm proved that the model is more stable and there was scope for optimization The Pitman arm is optimized. The weight of original model is $974 \mathrm{gm}$ and that of the optimized model is $840 \mathrm{gm}$. Weight of the component is reduced successfully upto $14 \%$ after optimization.

2. This optimized model is when tested, the strain value after the analysis using ANSYS is 1108.0 microstrain and that of the experimental testing is 1024.39 microstrain.

3. The comparison, between fatigue life results of existing and optimized pitman arm has been performed and it is observed that the pitman arm is having infinite life.

4. The above study confirmed that optimized pitman arm is structurally stable with good fatigue life.

\section{ACKNOWLEDGEMENT}

The research support provided by the Sinhgad Academy of Engineering is greatly appreciated. Also, special thanks to the Yogeshwar steels and NDT testing laboratory, pune for providing machining and testing support respectively.

\section{REFERENCES}

[1] Cristina Elena Popa, "Steering System and Suspension Design for 2005 Formula SAE-A Racer Car".

[2] Pradeep B Patil, P. D. Darade, K. R. Jagtap, D. N. Korade, "Modal Analysis, Fatigue Analysis and Optimization of Pitman Arm Using FEM", International Journal of Research and Scientific Innovation (IJRSI) | Volume V, Issue IX, September 2018 | ISSN 2321-2705.

[3] Sijith PM ShashankGawade S.S Kelkar CAE Analysis and Structural Optimization of PitmanArm International Engineering Research Journal, March 2018,1-5

[4] Gang Qin, Ying Sun, Yunqing Zhang and Liping Chen, "Analysis and Optimization of the Double-Axle Steering Mechanism with Dynamic Loadsll, The Open Mechanical Engineering Journal, 2012, 6, (Suppl 1-M2) 26-39.

[5] V.D.Thorat, S.P.Deshmukh, "Rigid Body Dynamic Simulation of Steering Mechanism", International Journal of Research in Engineering \& Advanced Technology, Volume 3, Issue 1, Feb-Mar, 2015, ISSN: $2320-8791$

[6] Lizbeth Huerta Larumbe, Eduardo Hurtado Delgado, M. Alvarez-Vera, Pedro Pérez Villanueva, "Forming process using austempered ductile iron (ADI) in an automotive Pitman arm", Int J AdvManufTechnol (2017) 91:569-575. 